\title{
Targeted mutations in the Caenorhabditis elegans POU homeo box gene ceh-18 cause defects in oocyte cell cycle arrest, gonad migration, and epidermal differentiation
}

\author{
David Greenstein, ${ }^{1,2,6}$ Steven Hird, ${ }^{1,3}$ Ronald H.A. Plasterk, ${ }^{4}$ Yoshiki Andachi, ${ }^{5}$ Yuji Kohara, ${ }^{5}$ \\ Benny Wang, ${ }^{1}$ Michael Finney, ${ }^{1}$ and Gary Ruvkun ${ }^{1}$ \\ ${ }^{1}$ Department of Molecular Biology, Massachusetts General Hospital, Boston, Massachusetts 02114 USA; Department \\ of Genetics, Harvard Medical School, Boston, Massachusetts 02115 USA; ${ }^{4}$ Netherlands Cancer Institute, 1066 CX \\ Amsterdam, The Netherlands; ${ }^{5}$ DNA Research Centre, National Institute of Genetics, Mishima 411, Japan
}

We used targeted gene inactivation to analyze the function of a Caenorhabditis elegans POU gene, ceh-18, and to dissect its functional domains in vivo. In ceh-18 mutants, oocytes exhibit an incompletely penetrant failure to arrest in diakinesis of meiotic prophase $I$ and instead undergo multiple rounds of DNA replication without cytokinesis. ceh-18 is expressed in the gonadal sheath cells that signal the oocyte, but not in the oocyte. This suggests that ceh-18 affects, directly or indirectly, a sheath cell signal that causes oocytes to maintain diakinesis arrest. ceh-18 also participates in directing gonad migration and in specifying the differentiated phenotypes of epidermal cells during postembryonic development. Analysis of targeted deletions that disrupt half of the POU domain selectively by deleting either the POUhd or the POUsp alone, indicates that each CEH-18 POU subdomain is sufficient for partial activity in vivo.

[Key Words: POU domain; germ-line development; meiotic arrest; oocyte; DNA endoreduplication; homeo domain]

Received May 17, 1994; revised version accepted July 6, 1994.

We have analyzed the in vivo role of a new member of the POU class of homeo box-containing genes, ceh-18, using a targeted gene knockout strategy in Caenorhabditis elegans (Zwaal et al. 1993). Transcription factors of the POU class of homeo box-containing genes have been implicated in the specification and proliferation of particular cell types (Rosenfeld 1991; Ruvkun and Finney 1991). Here we report an unexpected connection between the C. elegans POU gene ceh-18 and cell cycle control in oogenesis.

Oocyte arrest in meiosis is a universal feature of reproduction in both invertebrates and vertebrates (Masui and Clarke 1979). Meiotic arrest is normally relieved with ovulation and fertilization. Biochemical and molecular analysis in vertebrates has established that release from meiotic arrest in oocytes is under hormonal control that triggers a kinase cascade including the Mos kinase (Sagata et al. 1988, 1989) followed by activation of the maturation promoting factor (MPF) (Smith 1989). In con-

Present addresses: ${ }^{2}$ Department of Cell Biology, Vanderbilt University School of Medicine, Nashville, Tennessee $37232 \mathrm{USA}^{3}{ }^{3} \mathrm{MRC}$ Laboratory of Molecular Biology, Cambridge CB2 2QH, UK. trast, less is known about the molecular mechanisms by which oocyte arrest in meiotic prophase I is established and maintained. Here we report that targeted ceh-18 mutations lead to a cell cycle defect in oocytes such that this meiotic arrest point can be bypassed without fertilization. We determined that oocytes in ceh-18 mutants variably undergo multiple rounds of DNA replication (DNA endoreduplication) without karyokinesis or cytokinesis and become polyploid. We also show that ceh18 mutants exhibit an incompletely penetrant maternal effect lethality. Thus, ceh-18 affects two disparate aspects of oocyte differentiation: regulating both the oocyte cell cycle and the subsequent embryogenesis. Surprisingly, ceh-18 is not expressed in the oocyte but, rather in the gonadal sheath cells that encircle the oocyte. Recently, laser ablation of sheath cells or sheath cell precursors has been shown to result in an oocyte DNA endoreduplication phenotype (J. McCarter, R. Francis, and T. Schedl, pers. comm.). Taken together, these results suggest that ceh-18 affects sheath cell to oocyte signals that regulate the oocyte cell cycle as well as early developmental events of the embryo.

Targeted ceh-18 mutations also allowed us to dissect 
functionally the ceh-18 POU domain in vivo. The POU domain is a bipartite DNA recognition domain that consists of a POU-specific region (POUsp) and a POU homeo domain (POUhd) separated by a linker region (Rosenfeld 1991; Ruvkun and Finney 1991). Analysis of targeted deletions that disrupt selectively either the POUhd or the POUsp alone suggest that each subdomain is sufficient for partial activity in vivo.

\section{Results}

ceh-18 defines a new POU class gene

We isolated a novel member of the POU class of homeo box genes using degenerate oligonucleotide probes (Bürglin et al. 1989) from the helix-3 region of the POUhd to screen a $C$. elegans cDNA library. Several independent clones were isolated that correspond to a single locus and encode a new type of POU gene as revealed by DNA sequence analysis (Fig. 1A). We have named this gene ceh-18 (for C. elegans homeo box). An alignment of the encoded protein $\mathrm{CEH}-\overline{1} 8$ with other POU proteins indicates that the CEH-18 POUsp is most closely related to the vertebrate genes Oct-1,2 and the related Skn-1, sharing $78 \%$ amino acid identity over 75 amino acids (Fig. 1B). In this domain, $\mathrm{CEH}-18$ is less related to the other $C$. elegans POU proteins, UNC-86 and CEH-6, than it is to
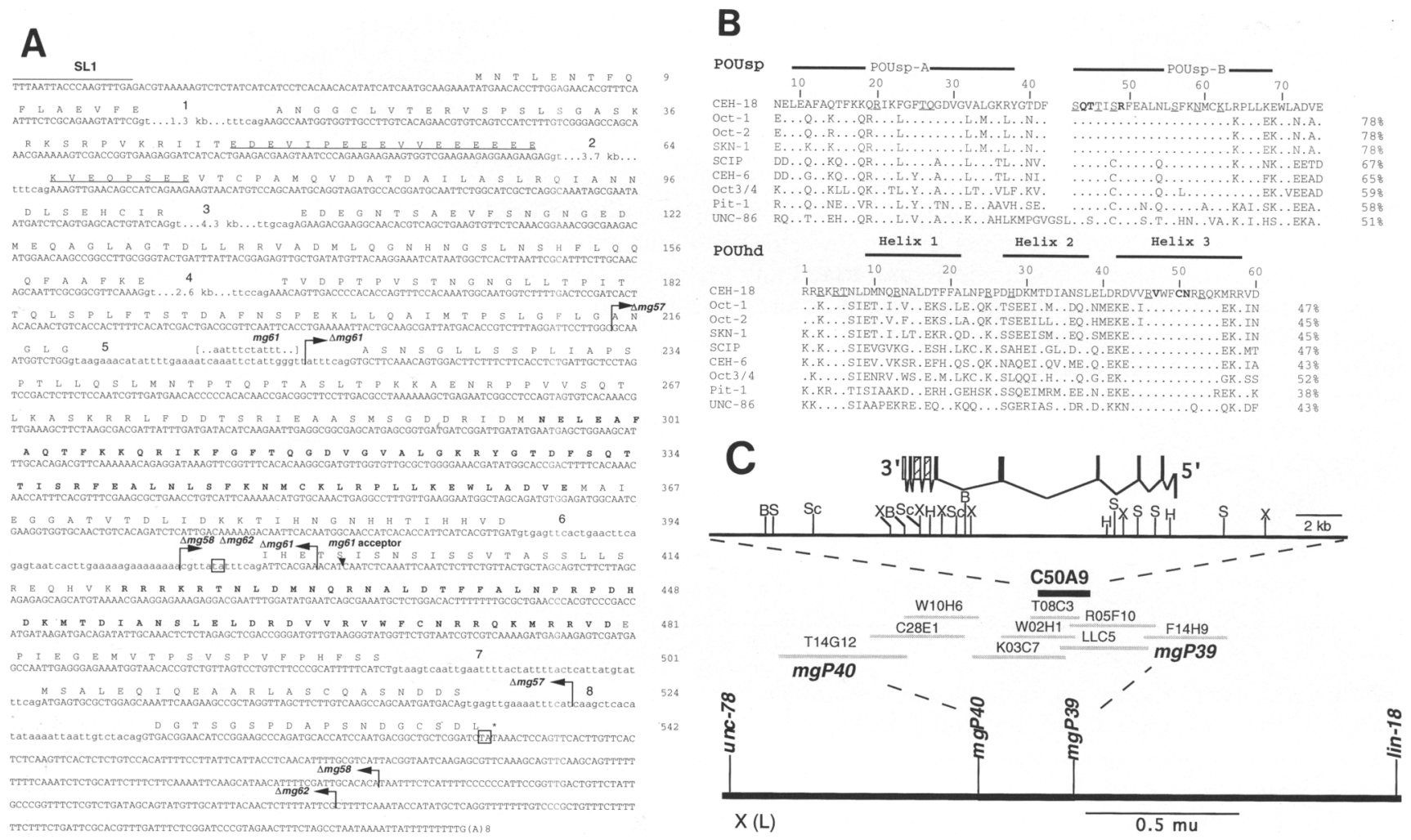

Figure 1. Molecular structure of $c e h-18$. (A) Sequence analysis of $c e h-18$. A composite of $c e h-18$ cDNA sequence, genomic sequence, and the deduced CEH-18 protein sequence is shown with key elements highlighted. Amino acids in the POU domain are in bold with the exception of amino acids in the linker region between the POUsp and the POUhd. The SLl trans-spliced leader sequence found at the $5^{\prime}$ end of the largest ceh-18 cDNA is overlined. An acidic stretch of amino acids is underlined. The numbering refers to the cDNA sequence and excludes the introns. The TA dinucleotides at which pk37::Tc1 (intron 6) and ms2::Tc1 (penultimate codon) inserted are boxed. The deletion endpoints are indicated for the respective alleles. The novel splice acceptor sequence in ceh-18(mg61) is indicated $(\nabla)$. Three clustered point mutations in intron 5 found adjacent to the deletion junction in $m g 61$ are indicated. $(B)$ Comparison of the amino acid sequence of the CEH-18 POU domain with other POU proteins. The POUsp and the POUhd are aligned separately. The POUsp A region, POUsp B region, and helices 1-3 in the POUhd are represented by the identified bars. Amino acid positions are numbered to facilitate comparison with the Oct-1-octamer cocrystal structure (Klemm et al. 1994). Amino acid residues that make major groove contacts in the Oct-octamer cocrystal structure are in bold, and amino acid residues that make phosphate contacts are underlined. Positions with identical amino acids to CEH-18 are represented by dots. The percentage amino acid identity to CEH-18 is listed next to each sequence. References: Oct-1 (Scheidereit et al. 1988; Sturm et al. 1988), Oct-2 (Clerc et al. 1988; Ko et al. 1988; Müller et al. 1988), Skn-1 (Andersen et al. 1993), SCIP (Monuki et al. 1990), CEH-6 (Bürglin et al. 1989), UNC-86 (Finney et al. 1988), Oct-3/4 (Okamoto et al. 1990; Rosner et al. 1990, Scholer et al. 1990), Pit-1 (Bodner et al. 1988; Ingraham et al. 1988). (C) Physical and genetic maps in the ceh-18 region. The top line is the gene structure with exons as boxes separated by introns. The direction of transcription is from right to left. The second line is the restriction map of the genomic cosmid clone C50A9. (B) BamHI; (H) HindIII; (S) SalI; (X) XbaI; (Sc) SacI. The third line is the physical map showing the positions of mgP40 and mgP39. The fourth line is the genetic map of a portion of the left end of the $\mathrm{X}$ chromosome. 
these vertebrate proteins. The nonconserved linker between the CEH-18 POUsp and the POUhd is 57 amino acids, the longest reported linker between the two independent domains. In addition, the CEH-18 POUhd is more divergent than the POUsp, sharing only $40-50 \%$ amino acid identity with other POUhds. Thus, CEH-18 defines a new POU class. The crystal structure of the Oct-1 POU domain bound to the octamer site has been determined recently (Klemm et al. 1994). All of the amino acids in both the POUsp and the POUhd of Oct-1 that were observed to make major groove base contacts are identical in CEH-18 (Fig. 1B). Amino acid side chains that were observed to make phosphate contacts are either identical in $\mathrm{CEH}-18$ or replaced by conservative amino acid substitutions. In contrast, helices 1 and 2 of the POUhd are divergent.

We determined the genetic and physical map positions of ceh-18 to analyze whether ceh-18 was defined by a previously isolated mutation. Genomic cosmid clones bearing ceh-18 (C50A9 and LLC5) were isolated. ceh-18 has 9 exons, 8 introns, and an outron for SL1 trans-splicing that together span $13 \mathrm{~kb}$, and is contained within the cosmid C50A9 (Fig. 1C). The cosmids C50A9 and LLC5 were fingerprinted and physically located to a region on the left end of the X chromosome (A. Coulson, pers. comm.). To determine the genetic map position of ceh18 , we correlated the genetic and physical maps within this region. We detected two restriction fragment length polymorphisms (RFLPs) between the interbreeding strains Bristol and Bergerac using ceh-18 flanking cosmids as probes. The genetic map position of ceh-18 was ascertained by genetically mapping these flanking RFLPs to the unc-78-lin-18 interval (Fig. 1C) using five- factor crosses. Because no candidate genes have been reported in this interval (J. Hodgkin et al., pers. comm.), ceh-18 must define a new gene.

\section{Targeted deletions in ceh-18}

We sought targeted deletions in ceh-18 to elucidate its function in vivo. Three transposable element Tc1 insertions in ceh-18 were identified by PCR and recovered by sib-selection (see Materials and methods). These Tc1 insertions were positioned molecularly in intron 4 [ceh18(ms1)::Tc1], intron 6 [ceh-18(pk37)::Tc1], and the penultimate codon [ceh-18(ms2)::Tc1] of ceh-18 (Fig. 2). These Tc1 insertions did not lead to a mutant phenotype and do not disrupt the function of ceh-18. Tc1 insertions have been observed to be excised from the primary transcript by mRNA splicing, sometimes resulting in a mature transcript that confers gene activity (Rushforth et al. 1993); however, Tc1 excision can result in deletions (Kiff et al. 1988; Zwaal et al. 1993). Therefore, we used the Tc1 insertions as starting points to isolate deletions in ceh-18-coding sequences. The transposable element insertion in ceh-18(pk37::Tc1) is in the 59-bp intron that lies between the exons that encode the POUsp and the POUhd, respectively, such that deletions resulting from imprecise loss of this transposable element would be likely to remove important coding sequences. We isolated four ceh-18 deletion alleles (mg57, mg58, mg61, and mg62) using multiple rounds of PCR and subsequent sib-selection (Fig. 2). All of the deletions were isolated under conditions in which the particular ceh-18 deletion was heterozygous to an undeleted chromosome and thus
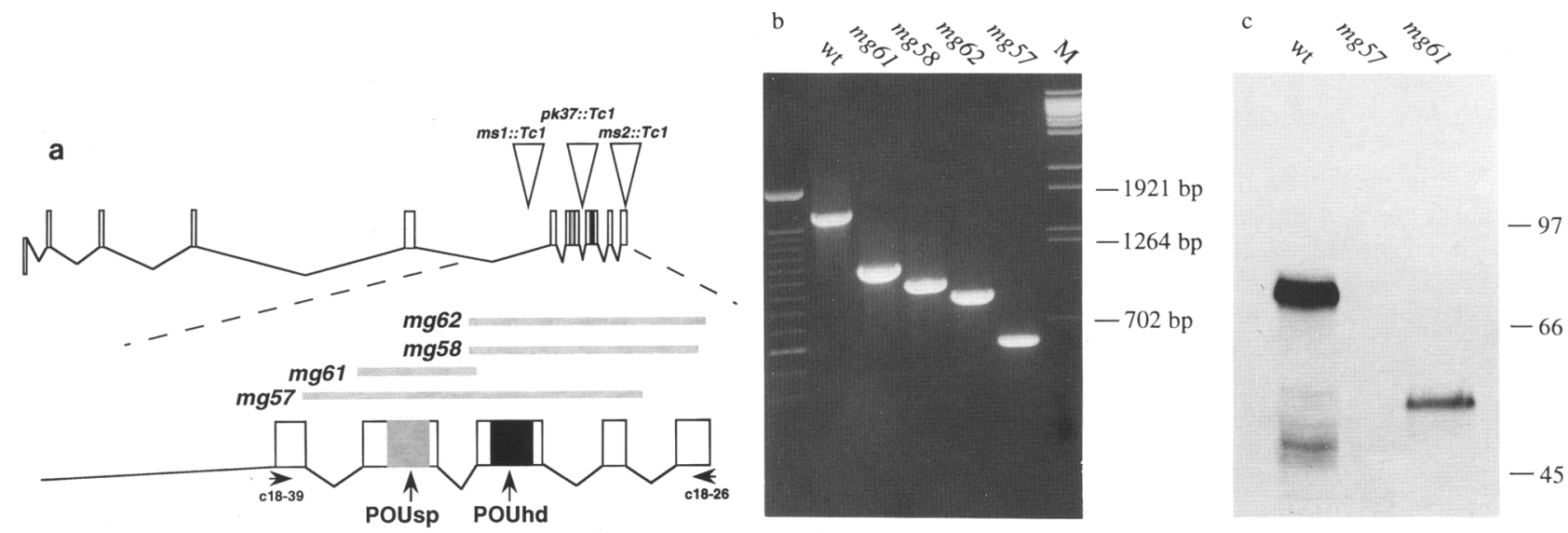

Figure 2. Targeted deletions in ceh-18. (A) Molecular analysis of Tc1 insertions and targeted deletions. The positions of the Tc1 insertions in ceh-18 are indicated above the genomic structure. All three Tc1 inserts are in the same orientation relative to the exons (denoted by boxes separated by introns), with the first base of Tc1 closest to the $5^{\prime}$ end of the gene. (Bottom) A close-up of the portion of the gene encoding the POUsp (shaded portion) and the POUhd (solid portion). The nucleotide sequences deleted in the various deletions alleles are indicated by shaded bars above the genomic structure. The precise limits of the deletions are shown in Fig. 1 . The positions of the PCR primers c18-39 and c18-26, which were used to isolate the deletion alleles, are indicated. $(B)$ PCR analysis of ceh-18 deletions. Single-worm PCR reactions were carried out with c18-39 and c18-26 primers and analyzed on an ethidium-stained agarose gel. Each lane is labeled with the genotype of the worm analyzed. Lane $M$ contains the indicated DNA molecular mass markers. $(C)$ Western blot analyis of targeted deletions. Each lane is labeled with the genotype of the stain tested. The positions of molecular mass markers $(\mathrm{kD})$ are indicated at right. 
could be isolated without regard to the resulting phenotype.

Each of the mutations was outcrossed to wild type at least seven times to remove any unlinked mutations. In addition, any linked mutations were crossed off the arms of the $\mathrm{X}$ chromosome by selecting two recombination events each between ceh-18 and the flanking genetic markers unc- 78 or lon-2, respectively. The resulting ceh18 mutant strains are homozygous viable, yet exhibit incompletely penetrant sterile and lethal phenotypes, and are sluggish (Table 1). These phenotypes include hermaphrodite sterility, maternal effect embryonic lethality, and larval arrest. Each of these phenotypes is recessive to wild type. Several lines of evidence suggest that these phenotypes are caused by the deletions in ceh-18: (1) Multiple independently isolated alleles exhibit the same set of phenotypes, although they vary in severity depending on how much of the POU domain is deleted (see below); (2) the mutant phenotypes are genetically inseparable from the deletions; (3) independent ceh-18 alleles fail to complement; thus, these phenotypes are unlikely to be caused by adventitious linked mutations; (4) the ceh-18 mutant phenotypes are rescued by extrachromosomal arrays of the cosmid C50A9 that contains ceh-18 (Table 1); and (5) molecular analysis of the dele- tion mutations indicated that the most severe allele, $m g 57$, is a $1.1-\mathrm{kb}$ deletion that removes the exons that encode the POUsp and the POUhd. This deletion is out of frame and is confined to ceh-18-coding sequences and the small introns 4-8. Because the mutation in ceh18(mg57) deletes the exons that encode the entire conserved POU domain, it is a good candidate for a null allele. Consistent with this idea, ceh-18(mg57) in trans to the deficiency syDf1 that uncovers ceh-18 flanking genetic markers shows the same set of phenotypes as ceh-18(mg57) homozygotes (data not shown). However, we cannot exclude the possibility that ceh-18(mg57) retains residual function in vivo in the absence of the POUsp and the POUhd.

\section{ceh-18 regulates both the oocyte cell cycle and oocyte function}

We analyzed germ-line development by Nomarski microscopy of live animals and DAPI staining of fixed preparations to investigate the basis for the hermaphrodite sterility and the reduced and highly variable brood sizes in ceh-18 mutants. In wild type, the adult hermaphrodite gonad consists of two symmetric ovotestes, or gonad arms (Hirsh et al. 1976; Kimble and Hirsh 1979) (see Fig.

Table 1. Phenotypes of ceh-18(lf) mutants

\begin{tabular}{|c|c|c|c|c|c|c|}
\hline Genotype & + & $+/ m g 57$ & mg57 & $m g 57 \cdot m g E x 92$ & $m g 58$ & $m g 61$ \\
\hline Eggs laid/hermaphrodite & $245 \pm 33$ & $258 \pm 17$ & $76 \pm 44^{a}$ & $174 \pm 28^{\mathrm{b}}$ & $225 \pm 98^{\mathrm{b}}$ & $222 \pm 48^{b}$ \\
\hline Embryonic lethality & $0.4 \pm 0.4 \%$ & $0.7 \pm 0.6 \%$ & $15 \pm 10 \%^{a}$ & $2 \pm 1 \%$ & $6 \pm 5 \%$ & $6 \pm 2 \%$ \\
\hline Sterility & $0.2 \pm 0.4 \%$ & $0 \%$ & $11 \pm 8 \%^{a}$ & $0 \%{ }^{b}$ & $5 \pm 9 \%$ & $2 \pm 2 \%$ \\
\hline Larval arrest & $0.1 \pm 0.2 \%$ & N.D. & $15 \pm 14 \% \%^{a}$ & N.D. & $1 \pm 1 \%$ & $1 \pm 1 \%$ \\
\hline Gonad arms with polyploid oocytes ${ }^{\mathrm{c}}$ & $0 \%^{\mathrm{d}}$ & $0 \%^{d}$ & $41 \%$ & $0 \%^{d}$ & $12 \%^{d}$ & $7 \%^{d}$ \\
\hline Migrations defective gonad $\operatorname{arms}^{c}$ & $0 \%{ }^{d}$ & $0 \%^{d}$ & $27 \%$ & $8 \%{ }^{\mathrm{d}, \mathrm{e}}$ & $6 \%$ d & $2 \%^{d}$ \\
\hline
\end{tabular}

Numbers of eggs laid by wild-type $(n=3)$, ceh-18(mg57) lon-2(e678)/ $(n=9)$, ceh-18(mg57) $(n=10)$, ceh-18(mg57); $m g E x 92(n=$ $2)$, ceh-18(mg58) $(n=10)$, and ceh-18(mg61) $(n=5)$ hermaphrodites and the phenotypes exhibited by these progeny. Hermaphrodites were picked as L2-L3 animals and transferred to fresh plates at 12 -hr intervals and grown at $21^{\circ} \mathrm{C}$ in a constant temperature room, and the numbers of eggs laid were counted. ceh-18(mg57) lon-2(e678)/ + hermaphrodites were the Fl cross progeny of wild-type males and ceh-18(mg57) lon-2(e678) hermaphrodites. (+) The wild-type N2 strain received from the MRC-LMB (gift of T. Barnes). Plates were checked for hatching 24 and $48 \mathrm{hr}$ after removing the parent. All the hatching embryos hatched within the first $24 \mathrm{hr}$ of removing the parent. Embryonic lethality was measured as the percentage of embryos that failed to hatch by $24 \mathrm{hr}$ after removing the parent. Hatching larvae were picked to individual plates. Larval arrest was measured as the precentage of hatching L1 larvae that died at the Ll stage or were younger than L4 animals 1 week after removing the parent. Sterility was measured as the precentage of animals that yielded no viable progeny by 1 week after removing the parent. For $+/ m g 57$, the sterility refers to 150 hermaphrodites of genotype ceh-18(mg57) lon-2(e678)/ +. An extrachromosomal array (mgEx92) of the ceh-18-containing cosmid C50A9 was constructed by coinjection of C50A9 $(10 \mu \mathrm{g} / \mathrm{ml})$ and the rol.6 transformation marker pRF4 $(50 \mu \mathrm{g} / \mathrm{ml})$. Control experiments indicated that the rol-6 transformation marker alone did not rescue the ceh-18 mutant phenotype (data not shown). For ceh-18(mg57); mgEx 92, the sterility value refers to the $m g E x 92$ bearing progeny only $(n=144)$. $m g 57$; $m g E x 92$ segregated $\sim 50 \% m g E x 92$ bearing progeny in this experiment. (N.D.) these larval arrest values were not determined quantitatively. The percentage of gonad arms that contained polyploid oocytes and the percentage of gonad arms that were defective in gonad migration were determined by microscopic examination of adult animals from mixed stage populations that were fixed and stained with DAPI. The percentage of gonad arms with polyploid oocytes was scored in adults containing at least three oocytes per gonad arm.

${ }^{\text {a }} P<0.01$ compared with wild type.

b $P<0.01$ when compared with $m g 57$. $P$ values were determined using Student's $t$-test with appropriate modifications for proportional data.

${ }^{c}$ Greater than 94 gonad arms were scored in each case.

d $p<0.01$ compared with the value for $m g 57$ using the $\chi^{2}$ test.

'The gonad migration defects seen in $m g 57 ; m g E x 92$ were also qualitatively less severe than those seen in mg57 alone. ceh-18(mg57) males mate at $100 \%$ efficiency when quantitatively compared (Hodgkin 1983) with wild-type males. 
3 for a representation of the gonad of the adult hermaphrodite). The gonad arms originate near the center of the worm along the anterior-posterior axis. One arm grows in an anterior direction, the other in a posterior direction (Fig. 3; proximal arm). Both arms then migrate dorsally, bend $90^{\circ} \mathrm{C}$, and grow back toward the mid-body region in the L4 larval stage (Fig. 3; distal arm). Germ-line stem cells proliferate mitotically and then enter meiosis, giving rise to sperm in the L4 larval stage. Oocytes are then formed in the adult stage from the next series of germline stem cells. There is a spatial and temporal gradient of meiosis in the wild-type gonad such that germ-line stem cells enter meiosis in the distal arm of the gonad, pass into the pachytene stage more proximally, and are arrested in the final stage of meiotic prophase I /diakinesis) in the proximal arm of the gonad, just distal to the spermatheca. Oocytes are fertilized by moving through the spermatheca that contains sperm (Hirsh et al. 1976; Ward and Carrel 1979). The passage into the spermatheca relieves meiosis I arrest and allows fertilization. There is no arrest in meiosis II in C. elegans.

In ceh-18 mutants, sperm differentiate as in wild type during the L4 larval stage. The sperm-to-oocyte switch in adulthood is unaffected. However, the terminal differentiation of the oocyte is severely affected. The proximal region of the gonad is often swollen and enlarged with misshapen oocytes. Staining of fixed preparations of ceh18 mutants with the DNA-specific fluorochrome DAPI indicated that $41 \%$ of mature adult hermaphrodite gonad arms contained polyploid oocytes (Tables 1 and 2). The fact that ceh-18 mutant polyploid oocytes are observed only in the proximal and not in the distal arm of the gonad suggests that they have entered meiosis but are defective in maintaining diakinesis stage arrest (Fig. 4 and Table 1). In addition, the polyploid germ-line nuclei are only associated with maturing oocytes that have cellularized, suggesting that syncytial mitotic germ nuclei are not the source of polyploid nuclei. These defective oocytes appear not to complete meiosis because they do

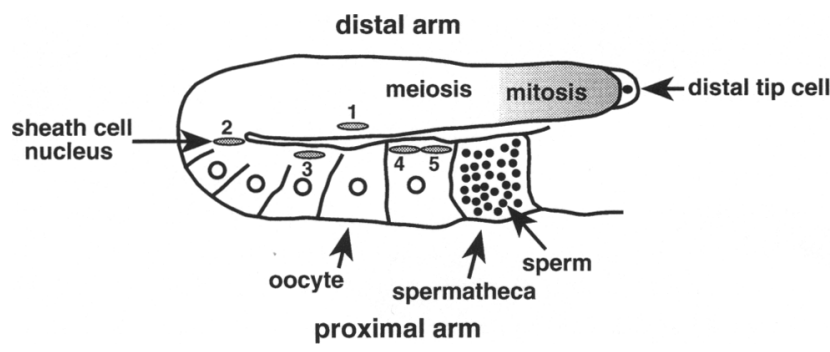

Figure 3. Representation of one of the two gonad arms of the adult hermaphrodite. Germ-line stem cells proliferate mitotically in the distal arm of the gonad near the dtc and enter meiosis more proximally. Oocytes arrested in the diakinesis stage of meiotic prophase I are found in the proximal arm of the gonad, just next to but outside of (distal to) the spermatheca that contains the sperm. The position of one of each pair of somatic gonadal sheath cell nuclei [numbered 1-5 (as in Kimble and Hirsh 1979|l is indicated. The sheath cells and the dtc express ceh-18, but oocytes do not (see text and Fig. 5).
Table 2. Phenotypic analysis of gonadal sheath cells

A. Analysis of sheath cell defects in ceh-18(mg57)

\begin{tabular}{lcccl} 
& & \multicolumn{2}{c}{ Arms } & \\
\cline { 3 - 4 } & $\begin{array}{c}\text { Total } \\
\text { gonad } \\
\text { Genotype }\end{array}$ & $\begin{array}{c}\text { with only } \\
\text { normal } \\
\text { sheath } \\
\text { nuclei }^{\mathrm{a}}\end{array}$ & $\begin{array}{c}\text { with } \\
\text { abnormal } \\
\text { sheath } \\
\text { nuclei }^{\mathrm{b}}\end{array}$ & $\begin{array}{l}\text { Not } \\
\text { scorable }\end{array}$ \\
\hline+ & 51 & $49(96 \%)$ & $2(4 \%)^{\mathrm{d}}$ & 0 \\
ceh-18(mg57) & 93 & $64(69 \%)$ & $15(16 \%)^{\mathrm{d}}$ & $14(15 \%)$
\end{tabular}

B. Breakdown of sheath cell defects in ceh-18(mg57) according to polyploid oocyte phenotype

\begin{tabular}{lcc} 
& \multicolumn{2}{c}{ Gonad arms } \\
\cline { 2 - 3 } & $\begin{array}{c}\text { with polyploid } \\
\text { oocytes }\end{array}$ & $\begin{array}{c}\text { without polyploid } \\
\text { oocytes }\end{array}$ \\
\hline $\begin{array}{c}\text { Arms with only normal } \\
\text { sheath nuclei }\end{array}$ & $20(51 \%)$ & $44(81 \%)$ \\
$\begin{array}{c}\text { Arms with abnormal } \\
\text { sheath nuclei }\end{array}$ & $5(13 \%)^{\mathrm{b}}$ & $10(19 \%)^{\mathrm{e}}$ \\
Not scorable $^{\mathrm{c}}$ & $14(36 \%)$ & 0 \\
Total gonad arms $^{\mathrm{f}}$ & $39(100 \%)$ & $54(100 \%)$ \\
\hline
\end{tabular}

Sheath cell nuclei were microscopically examined in DAPIstained fixed preparations of dissected gonads from adult hermaphrodites.

${ }^{a}$ Gonad arms were scored as normal if they contained 10 sheath cell nuclei of wild-type size in the correct positions /see Kimble and Hirsh 1979|.

${ }^{b}$ Gonad arms were scored as abnormal if they contained fewer or more than 10 sheath cell nuclei or if the sheath cell nuclei were small in size or misplaced.

${ }^{\mathrm{c} G o n a d}$ arms that contained polyploid oocytes were often unscorable because they contained lysed and nonlysed polyploid oocyte nuclei which obscured visualization of sheath cell nuclei.

${ }^{\mathrm{d}} P<0.05$ when these values were compared using the $\chi^{2}$ test. 'These values were not significantly different when compared using the $\chi^{2}$ test.

${ }^{\mathrm{f}} 42 \%$ of the ceh-18(mg57) adult hermaphrodite arms contained polyploid oocytes.

not generate polar bodies as assayed by DAPI staining (data not shown). The conclusion that polar bodies are not generated by polyploid oocytes in ceh-18 mutants is provisional because additional defects in karyokinesis or cytokinesis might lead to fusion between polar bodies and the endoreduplicating nucleus, and consequently, we may have failed to observe them.

The ceh-18 defect is specific to meiosis in oogenesis and not in spermatogenesis, as males are unaffected and mate with wild-type efficiency (see legend to Table 1). Moreover, polyploid germ-line nuclei are never observed in hermaphrodites during the L4 larval stage, the time at which spermatogenesis occurs. These observations are consistent with the idea that ceh-18 is involved in the control of an arrest point specific to oogenesis, as in spermatogenesis there is no meiotic arrest point; unlike oocytes, sperm complete meiosis before fertilization.

The oocyte meiotic defect contributes to the small and 

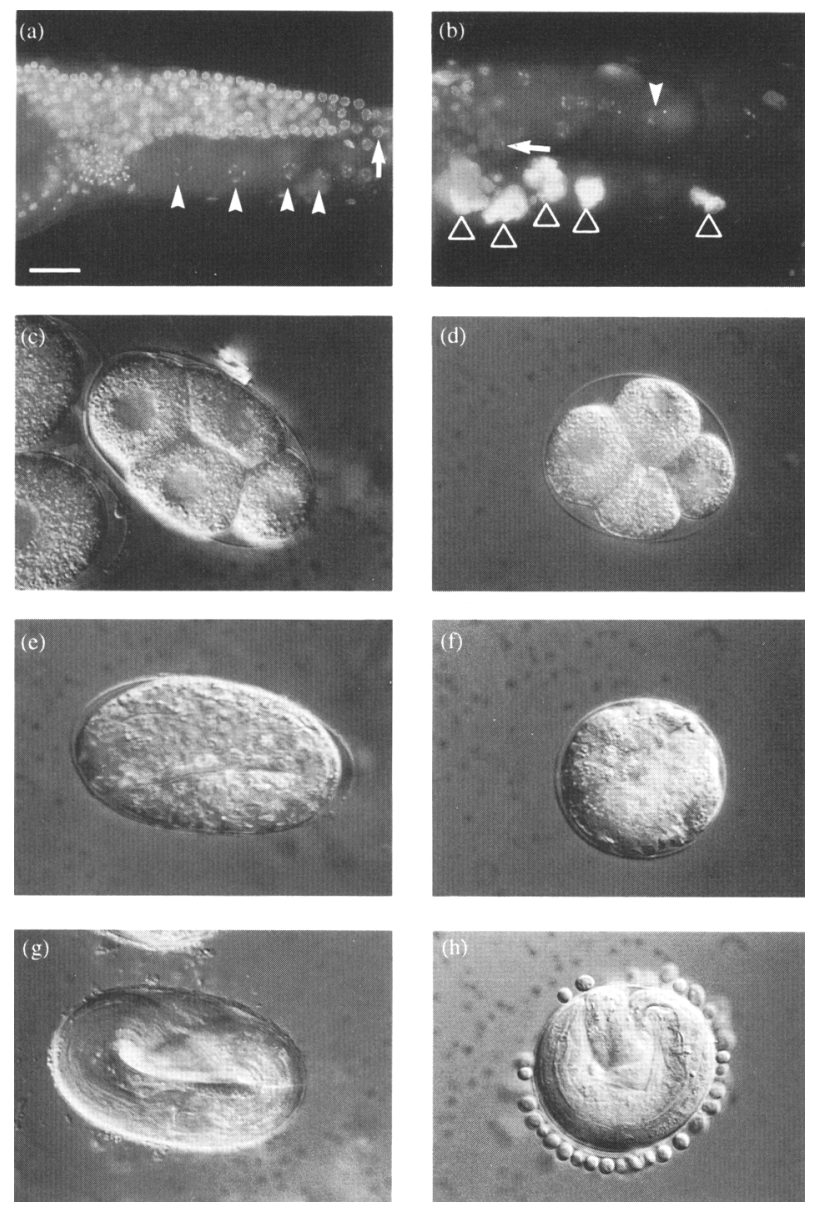

Figure 4. $c e h-18$ promotes terminal differentiation of the oocyte. $(a, b)$ Polyploid oocytes in ceh-18 mutants. DAPI staining of wild type $(a)$ and ceh-18(mg57) (b) adult hermaphrodite gonads. The open triangles show polyploid oocytes in ceh. 18(mg57). The solid arrowheads indicate diakinesis stage nuclei, and the small solid arrows indicate pachytene stage germ cell nuclei. $(c-h)$ Maternal effect embryonic lethality in ceh-18 mutants. Nomarski micrographs of wild-type $(c, e, g)$ and ceh18 (mg57) $(d, f, h)$ embryos at the four-cell stage $(c, d)$, twofold stage $(e, f)$, and threefold stage $(g, h)$. Note the symmetry of blastomeres in the $m g 57$ embryos. Bar, $50 \mu \mathrm{m}$. The debris outside of the embryo in $h$ is yeast cells that were inadvertently in the culture.

variable brood sizes in ceh-18 mutants. Polyploid oocytes were found distal to the spermatheca and never had eggshells, suggesting that they were unfertilized. When abnormal oocytes undergo DNA endoreduplicaton, they appear to block distal maturing oocytes from entering the spermatheca and being fertilized (Fig. 4). Eventually, the polyploid oocytes appear to lyse and DNA fills an expanded gonad. Each arm of the hermaphrodite gonad is independent and either or both can be sterile in ceh-18 mutants. If either gonad arm is fertile the hermaphrodite can produce viable progeny. The most severely affected ceh-18 mutant animals $(\sim 16 \%$ of adults) produce no fertilized eggs and lay no unfertilized oocytes.
In the hermaphrodite gonad, germ cells differentiate into both sperm and oocytes. Therefore, a possible explanation for the polyploid oocytes observed in ceh-18 mutants could be that the oocytes become activated by defective sperm or sperm products. To test this possibility, we examined double mutants between ceh-18(mg57) and the germ-line sex determination mutants fem1(hc17ts) and fem-2(b245ts) that produce no sperm (Nelson et al. 1978; Kimble et al. 1984). Polyploid oocytes were seen distal to the spermatheca in both double mutants, ceh-18(mg57); fem-1(hc17ts) and ceh-18(mg57); fem-2(b245ts) at the restrictive temperature, indicating that oocyte DNA endoreduplication can occur in the absence of sperm in the gonad. Thus, the oocyte cell cycle arrest defect is not caused by abnormal fertilization.

In addition to the meiotic defect, there is a mild germline hypoproliferation phenotype in ceh-18 mutants. Although germ-line stem cells proliferate, some animals have smaller gonads than wild type with fewer germ cells. The hypoproliferation phenotype seen in ceh-18 mutants is less severe than that caused by $g l p-1$ or $g l p-4$ mutations (Austin and Kimble 1987; Beanan and Strome 1992). This germ-line proliferation phenotype might be related to a defect in distal tip cell function (see below) or to a defect in the function of the gonadal sheath cells (J. McCarter, R. Francis, and T. Schedl, pers. comm.).

ceh-18 mutations also lead to an incompletely penetrant maternal effect embryonic lethality (Table 1). Approximately $15 \%$ of embryos from homozygous ceh18(mg57) mutant mothers fail to hatch (Table 1). This embryonic lethality was not rescued zygotically (data not shown). Therefore, we studied embryonic development in ceh-18 mutants by Nomarski microscopy. The terminal phenotype of embryonic lethal ceh-18 mutant embryos is heterogeneous with developmental arrest occurring at a variety of embryonic stages (Fig. 4). Most of these lethal embryos have a spherical shape in contrast to wild-type embryos that are oval in shape with the long axis corresponding to the anterior-posterior axis. The embryo derives its shape from an eggshell that it synthesizes within the first $30 \mathrm{~min}$ after fertilization. Therefore, both the early and heterogeneous phenotypes and the abnormal shape of embryonic lethal ceh-18 mutant embryos are consistent with a very early defect in embryogenesis and could result from an abnormal oocyte. The maternal effect embryonic lethality could be caused by aneuploidy or polyploidy as a secondary consequence of the oocyte meiotic cell cycle defect. However, we were unable to detect gross alterations in the ploidy of ceh-18 mutant embryos by DAPI staining. In addition, ceh-18 mutants do not have a Him (high incidence of males, karyotype $\mathrm{XO}$ ) phenotype indicating that the frequency of nondisjunction of the $\mathrm{X}$ chromosome was the same as in wild type. These data suggest that the embryonic lethality is not simply attributable to random aneuploidy as a consequence of earlier cell cycle defects.

\section{CEH-18 is expressed by the gonadal sheath cells}

To understand the basis for the gonadal defects in ceh-18 
mutants, we prepared antibodies specific for the portion of CEH-18 deleted in ceh-18(mg57) (referred to as $\alpha-\mathrm{CEH}-18 \Delta \mathrm{mg} 57$ antibodies) and used these antibodies to determine the ceh-18 expression pattern. These antibodies are specific for CEH-18, and there is no immunoreactivity in ceh-18(mg57) at any stage of development (Fig. 5; data not shown). In addition, these antibodies detect a protein of $\sim 70 \mathrm{kD}$ in Western blots of wild-type C. elegans, but not from ceh-18(mg57) (Fig. 2C); thus, this protein is encoded by $c e h-18$. In wild type, $\alpha-\mathrm{CEH}-$ $18 \Delta \mathrm{mg} 57$ antibodies detect $\mathrm{CEH}-18$ in the nuclei of the sheath cells of the somatic gonad (Fig. 5). In contrast, $\mathrm{CEH}-18$ is not detected in diakinesis stage oocytes, pachytene stage meitotic germ cells, mitotic germ cells,
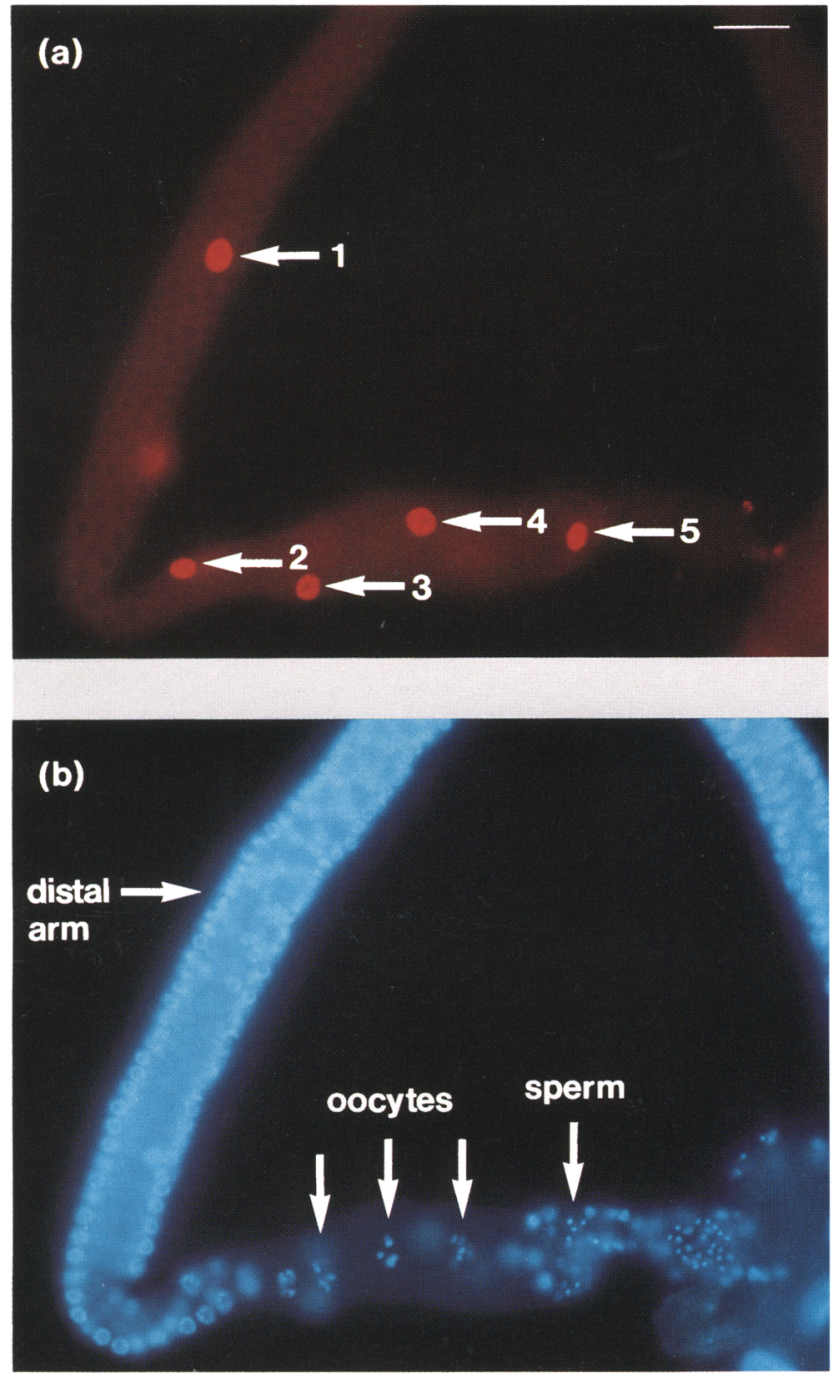
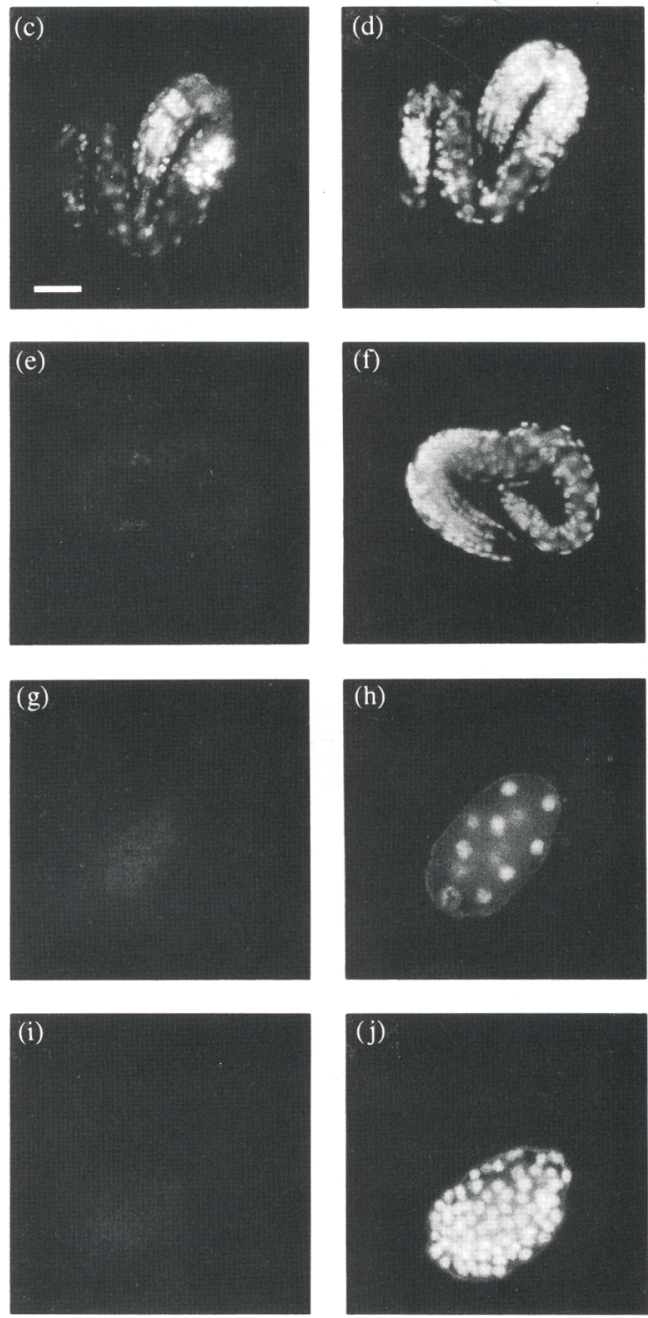

Figure 5. Immunofluorescence detection of CEH-18-expressing cells. $\mathrm{CEH}$-18-expressing cells were detected using $\alpha$-CEH-18Dmg57 antibodies to stain wild type $(a, c, g, i)$, or $c e h-18(m g 57)(e)$. Nuclei were also visualized with DAPI $(b, d, f, h, j)$. The same samples are shown in $a$ and $b$ (dissected gonad of adult hermaphrodite), $c$ and $d$ (wild-type threefold-stage embryo), $e$ and $f(c e h-18$ (mg57) threefoldstage embryo), $g$ and $h$ (wild-type 12-cell embryo), $i$ and $j$ (wild-type $\sim 150$-cell embryo). There are five pairs of gonadal sheath cells per gonad arm, designated 1-5 (see Fig. 3). Only one of each pair is shown; the other five nuclei are out of the plane of focus but also stain. The DAPI image in $b$ is in a slightly lower focal plane to show the diakinesis stage nuclei in the proximal arm of the gonad (indicated by arrows). The arrows mark CEH-18-expressing gonadal sheath cell nuclei, which are also numbered. The distal arm of the gonad containing pachytene stage and mitotic germ cell nuclei is indicated by an arrow. Sperm nuclei are indicated. The background in the germ-line cytoplasm is attributable to the secondary antibody. No staining was seen in ceh-18(mg57) at any stage of development (see text). Note CEH-18 is first expressed late in embryogenesis at the threefold stage, before hatching, and is absent from early embryos. At hatching, CEH-18 is most abundant in the pharyngeal muscle nuclei, the nuclei of the hypodermal syncytia (hyp 1-11), the nuclei of the seam cells, the P hypodermal blast cells, and the body muscle nuclei. CEH-18 is notably absent from nearly all neurons at this stage, although it is expressed by the anterior touch cells ALML/R. Bars, 50 and $25 \mu \mathrm{m}$, in $a$ and $c$, respectively. $a$ and $b$ were kindly provided by R. Francis and T. Schedl (Washington University School of Medicine, St. Louis, MO). 
mature sperm, or fertilized oocytes (Fig. 5; data not shown). These results suggest that ceh-18 regulates the oocyte cell cycle by acting in cells other than the oocyte. Germ-line stem cells differentiate into oocytes during the adult stage. We determined that $\mathrm{CEH}-18$ is present in sheath cell nuclei as early as the L4 stage (data not shown|, before the onset of oogenesis.

Electron micrographs of gonadal sections (Hirsh et al. 1976) have shown that the gonadal sheath cells encircle developing oocytes. Laser ablation of half of the sheath cells can phenocopy the oocyte DNA endoreduplication defect seen in ceh-18 mutants (J. McCarter, R. Francis, and T. Schedl, pers. comm.). This result suggests that the sheath cells are likely to signal the oocyte to maintain meiotic arrest before fertilization. In contrast to oocytes, sperm do not exhibit meiotic arrest and are unaffected by ceh-18 mutations. It is interesting to note that the male gonad lacks gonadal sheath cells and is sheathed only partially by the distal cells of the seminal vesicle. This is consistent with the idea of a sex-specific function, signaling to maintain oocyte meiotic arrest, for the gonadal sheath cells.

We considered three hypotheses to explain the meiotic arrest defect in ceh-18 mutants in the absence of ceh-18 expression in oocytes. In the first hypothesis, ceh-18 might affect the gonadal sheath cell lineages such that the correct number of sheath cells are not generated in ceh-18 mutants. According to this hypothesis, the oocyte meiotic arrest defect would be a secondary consequence of the absence of sheath cells. The second hypothesis we considered was that ceh-18 could function in the differentiation of sheath cells. According to this hypothesis, ceh-18 might affect directly or indirectly the production or transmission of sheath cell to oocyte signals that regulate meiotic arrest. A third hypothesis is that a meiotic arrest signal to the germ-line arises from elsewhere in the animal. Besides gonadal sheath cells, many other cells, including syncytial hypodermal cells (hyp 7), located throughout the body, also express ceh-18 (see Fig. 5 and legend). According to this hypothesis, ceh18 mutations would perturb the oocyte cell cycle by a different mechanism than the sheath cell ablations.

To distinguish between the first two hypotheses (e.g., lineage vs. differentiation), we analyzed the number, size, and positions of sheath cell nuclei in ceh-18(mg57) adult hermaphrodite gonads (Table 2). We determined that sheath cells are generated in ceh-18(mg57) hermaphrodites and that the majority of gonad arms contained wild-type numbers of sheath cell nuclei (10) located in the correct positions. Significantly, we observed many ceh-18 mutant gonad arms (20/39) that contained polyploid oocytes, yet had a normal number of gonadal sheath nuclei with wild-type morphology and positions (Table 2B). Thus, we conclude that the oocyte meiotic arrest phenotype is not a secondary consequence of changes in the lineages that generate the sheath cells. We also used anti-desmosomal monoclonal antibody MH27 to analyze the generation of spemathecal cells in ceh-18(mg57) hermaphrodites, as the lineages that generate the sheath cells also generate spermathecal cells
(Kimble and Hirsh 1979). We determined that ceh18(mg57) hermaphrodites contain the correct number of spermathecal cells, which further suggests that the sheath cell lineages are normal in ceh-18 mutants. However, we observed a small but significant percentage of ceh-18 mutant gonad arms $(16 \%)$ that were abnormal in that one or two sheath cell nuclei were small, misplaced, or missing. We observed one gonad arm that contained an extra sheath cell nucleus. Such defects were observed at a much lower frequency in wild-type gonads (Table 2). These observed sheath cell abnormalities were independent of the oocyte meiotic arrest defect. Our observation of ceh-18 mutant gonad arms that contained abnormal sheath cells is suggestive of a role for ceh-18 in the differentiation of sheath cells but not in their generation.

The maternal effect embryonic lethality that we observe, in principle could be attributable to ceh-18 action in the gonad, the embryo, or both. In wild-type embryos, $\mathrm{CEH}-18$ is first detected in the nuclei of many but not all cells late in embryogenesis, at the threefold stage before hatching (Fig. 5). However, we observed no ceh-18 expression at the early embryonic stages affected by ceh-18 mutations (Fig. 5). Because ceh-18 mutants often exhibit defects before the late embryonic stage when expression is first observed, ceh-18 might act in the gonadal sheath cells to regulate embryogenesis indirectly.

\section{ceh-18 functions in germ-line migration}

In addition to a defect in oogenesis, ceh-18 mutants exhibit an incompletely penetrant gonad migration defect. Approximately $27 \%$ of hermaphrodite mutant gonad arms migrate along abnormal trajectories, often migrating into the head or tail rather than reflexing into the mid body region as in wild type (Fig. 6 and Table 1). The gonad migration defective phenotype is not correlated with the sterile phenotype: We observed both sterile animals with normal gonad migration and fertile animals with abnormal gonad migration. Immunofluorescence detection of CEH-18 in migrating hermaphrodite gonads indicated that CEH-18 is expressed by the distal tip cell (dtc) of the somatic gonad from early L2 through the adult stage (Fig. 6). The dtc has been demonstrated to direct migration of the gonad (Kimble and White 1981). Therefore, a simple model is that $\mathrm{CEH}-18$ expression by the dtc might mediate its function in directing the migration of the gonad.

\section{ceh-18 regulates epidermal differentiation}

ceh-18 mutations result in an incompletely penetrant larval arrest phenotype that is observed most frequently as an L1 lethal phenotype (see Table 1). This larval arrest phenotype is not strictly zygotic. We were able to phenocopy this L1 lethal phenotype by expression of antisense ceh-18 mRNA from a heat shock promoter during the L1 larval stage (data not shown). Because CEH-18 is expressed widely in many epidermal cells at hatching (see Fig. 5), we analyzed the differentiation of lateral hypodermal seam cells in ceh-18 mutants. mAb NE2/1B4- 

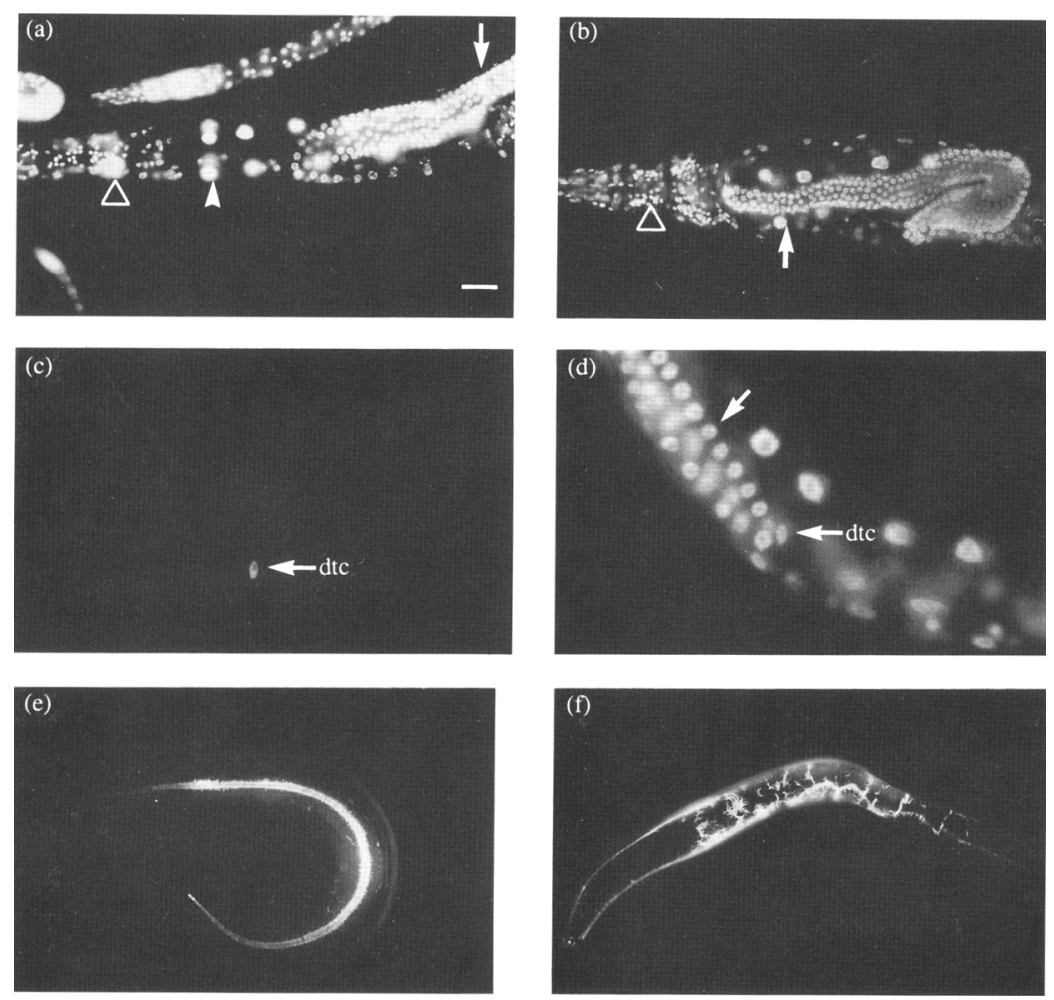

Figure 6. ceh-18 mutant phenotypes. Gonad migration in wild-type $(a)$ and ceh-18(mg57) $(b \mid$ adult hermaphrodites visualized by DAPI staining. An arrow marks the distal region of the anterior gonad arm. Note that in ceh-18(mg57), the distal arm of the gonad is positioned close to neurons in the nerve ring $(\Delta)$ and an anterior intestinal cell nucleus (arrow in $b$ ), whereas in wild type the distal gonad arm is positioned posterior to the anterior intestinal nucleus (arrowhead in a). Expression of CEH-18 in the dtc was detected using $\alpha$-CEH-18 $\Delta \mathrm{mg} 57$ antibodies in the developing gonad of a wild-type L3 larva $(c)$. (d) The DAPI stain of the same animal; the germ cell nuclei do not express CEH-18 (arrow). Lateral hypodermal seam cells in L1-stage larvae were analyzed in wild type $(e)$ and ceh-18(mg57) $(f)$ using immunofluorescence with mAb NE2/1B4-14. Bar, $50 \mu \mathrm{m}$. Anterior is to the left.
14 detects an unknown antigen in a characteristic pattern that is specific for the seam cells of the lateral epidermis (J. Rothman, pers. comm.). We observe that the components of the seam cell-specific antigen detected by NE2/1B4-14 are disorganized in ceh-18(mg57) (Fig. 6). Moreover, ectopic staining is seen in cells of the large hypodermal syncytium hyp 7 compared with wild type. This abnormality in hypodermal cell differentiation, as detected by NE2/1B4-14, is highly penetrant; 124 of 126 L1 stage animals were scored as abnormal. This suggests that $c e h-18$ is required for the structure and/or function of the L1-specific epidermis.

\section{Function of ceh-18 in the absence of a POUhd or POUsp}

We isolated two ceh-18 mutant alleles (mg58 and mg62) in which the seventh exon encoding the POUhd was deleted, but all exons 5 ' to exon 7 were intact, including the one encoding the POUsp domain (Figs. 1 and 2). We find that both ceh-18(mg58) and ceh-18(mg62) are less severe than ceh-18(mg57) but display the same range of phenotypes (Table 1 ; data not shown). Specifically, ceh18(mg58) and ceh-18(mg62) are more fertile, exhibit a reduction in the penetrance of the maternal effect embryonic lethality and larval arrest phenotypes, move better, and appear healthier upon examination under the dissecting microscope than ceh-18(mg57). Moreover, the penetrance of the oocyte DNA endoreduplication defect and the gonad migration defect were also reduced in both ceh-18(mg58) and ceh-18(mg62). Because ceh-18(mg57) is likely to be null, we infer that ceh-18(mg58) and ceh18(mg62) are both non-null alleles and, therefore, ceh-18 can have residual in vivo function in the absence of a homeo box.

Similarly, we isolated another mutant allele, ceh18(mg61), which deletes the POUsp but retains the POUhd and is also less severe than ceh-18(mg57) (see Table 1). ceh-18(mg61) results from a deletion that removes the splice acceptor sequence of intron 5 , all of exon 6 that encodes the POUsp, all of intron 6, and $9 \mathrm{bp}$ of exon 7. Because ceh-18(mg61) is less severe than ceh18(mg57) and because ceh-18(mg61) animals reacted with the $\alpha-\mathrm{CEH}-18 \Delta \mathrm{mg} 57$ antibodies on immunostaining (Table 1; data not shown), we considered the possibility that the ceh-18(mg61) transcript might be spliced so as to contain the homeo box. We characterized the spliced transcripts from ceh-18(mg61) using reverse transcription and PCR (RT-PCR). The results indicate that the extant splice donor in intron 5 in ceh-18(mg61) is spliced in-frame to the C-residue at the position 14 of exon 7 corresponding to the POU domain linker (see Fig. 1). The splice acceptor is $5^{\prime}$-TTACAT- $3^{\prime}$ instead of the consensus $5^{\prime}$-TTTCAG- $3^{\prime}$. We estimate that $\sim 30 \%$ of the message is spliced in this manner, and the remaining $70 \%$ is not spliced from the intron 5 donor (data not shown). The protein encoded by ceh-18(mg61), therefore, would contain a POUhd but not a POUsp. Western blot analysis of protein extracts prepared from the ceh18(mg61) mutant strains with the $\alpha-\mathrm{CEH}-18 \Delta \mathrm{mg} 57$ antibodies indicates that the encoded protein product is $\sim 20 \mathrm{kD}$ smaller in the mutant, consistent with the 
results of the RT-PCR experiment (see Fig. 2C). Because ceh-18(mg61) results in a less severe phenotype than ceh-18(mg57), we conclude that the POUhd in the absence of a POUsp is sufficient for partial ceh-18 activity in vivo. The $m g 58 / \mathrm{mg} 61$ trans-heterozygote exhibits a ceh-18 mutant phenotype, indicating that the encoded proteins, each of which exhibits partial function, are unable to compensate for one another.

\section{Discussion}

Reverse genetic approaches to analyze gene function directly are now possible in $C$. elegans using a targeted gene knockout strategy (Zwaal et al. 1993). We have taken this approach because many members of developmental control gene families have been defined molecularly, but not genetically, especially by the C. elegans genome sequencing project (Sulston et al. 1992). For example, only one-third of the known $C$. elegans homeo box-containing genes have been defined genetically (Bürglin et al. 1989). We have used this approach both to study the in vivo role of a divergent POU gene, ceh-18, and to dissect its functional domains in vivo.

We find that ceh-18 loss-of-function (If) mutations are pleiotropic and incompletely penetrant, affecting a number of developmental processes. Analysis of these mutations suggests that ceh-18 plays several roles in the development of the hermaphrodite germ line. We find that ceh-18(lf) mutations profoundly affect the meiotic cell cycle during oogenesis. In the absence of functional CEH-18, oocytes exhibit a meiotic cell cycle defectthey can undergo multiple rounds of DNA replication in the absence of fertilization and without completing meiosis. When oocytes undergo DNA endoreduplication in ceh-18 mutants, it is not clear whether there are repeated rounds of $S$ phase or rather uncontrolled DNA replication. Our data do not differentiate between removal of a block to $\mathrm{S}$ phase in oogenesis or ectopic production of an $S$ phase signal.

In contrast to ceh-18 mutants, in wild type the meiotic cell cycle is modified to allow two rounds of chromosome segregation without intervening DNA replication. This difference suggests that ceh-18 mutations may define a meiotic cell cycle checkpoint in oogenesis in accordance with the definition of an If mutation that removes a dependent event in the cell cycle (Hartwell 1991), in this case, the dependence of S phase on completion of the events of meiosis and fertilization. Another possibility is that ceh-18 mutations disrupt a meiotic cell cycle arrest point and that there is no checkpoint in oogenesis. In fact, wild-type oocytes are released from diakinesis arrest only after they leave the proximal arm of the gonad and enter the spermatheca (Ward and Carrel 1979). Moreover, DNA endoreduplication can be observed in unfertilized oocytes of wild type that have been activated by entering a spermatheca that is depleted of sperm (Ward and Carrel 1979). However, in wild type this activation never occurs distal to the spermatheca, whereas in ceh-18 mutants we observe polyploid oocytes distal to the spermatheca, in the proximal arm of the gonad (Fig. 3).

Our data suggest that ceh-18 does not act within the oocyte to control its cell cycle, as ceh-18 is not expressed in the oocyte at the level of detection of immunostaining. Our results are more consistent with a nonautonomous role in oogenesis involving cell interactions between the ceh-18-expressing gonadal sheath cells and developing oocytes. Mosaic analysis ultimately will be important to determine whether the function of ceh-18 is nonautonomous with respect to the oocyte cell cycle defect. On the basis of laser ablation of gonadal sheath cells and sheath cell precursors, which results in an oocyte DNA endoreduplication phenotype, J. McCarter, R. Francis, and T. Schedl (pers. comm.) have proposed that the sheath cells signal to maintain oocyte meiotic cell cycle arrest. Thus, a possible molecular mechanism for action of $c e h-18$ in the gonadal sheath cells would be the control of signals for oocyte cell cycle arrest before fertilization. ceh-18 mutations could affect the production or transmission of these signals indirectly by altering sheath cell differentiation, or these signals could be directly downstream of $c e h-18$. It is well established that growth factors, such as transforming growth factor (TGF$\beta$ ), can arrest the cell cycle in $G_{1}$ (Kingsley 1994). Thus far, no growth factor has been described that confers diakinesis arrest in meiotic prophase I and prevents DNA endoreduplication. Our data imply the existence of such a sheath cell to oocyte signal, either directly or indirectly downstream of ceh-18.

In vertebrates, oocyte arrest in meiosis I can be released by progesterone treatment that leads to activation of PI3 kinase, Mos kinase, and ultimately MPF (Sagata et al. 1988, 1989; Smith 1989; Muslin et al. 1993b). Recent evidence has implicated an evolutionarily conserved protein kinase cascade, including Raf-1 protein kinase and MAP kinase in the progesterone-triggered signal transduction pathway in the oocyte that leads to the activation of MPF (Muslin et al. 1993a; Nebreda and Hunt 1993). Therefore, we suggest that the most likely explanation for the aberrant oocyte cell cycles in ceh-18 mutants is that there exists a defect in the production or transmission of the sheath cell signal that normally regulates the pathway to meiotic arrest and DNA replication inhibition in oocytes. Given the conservation of the signal transduction pathway by which oocyte maturation is achieved, it is tempting to speculate that the arrest mechanisms will also be conserved and may even involve negative controls on the maturation pathway.

In Drosophila, the interacting maternal effect genes gnu, pan gu, and plutonium have been shown to regulate DNA replication subsequent to oogenesis after completion of meiosis and during early embryogenesis (Freeman and Glover 1987; Shemanski and Orr-Weaver 1991). Recently, plutonium has been cloned and shown to encode an ankyrin repeat protein that has been proposed to function by binding and inhibiting the function of an essential DNA replication factor (Axton et al. 1994). If analogous factors are participating in oogenesis in C. elegans, they could also act in a pathway with ceh-18. 
ceh-18(lf) mutations also cause maternal effect embryonic lethality that taken together with the expression data are suggestive of somatic gonad to oocyte signaling. We observe that ceh-18 mutant embryos exhibit defects in embryogenesis long before the point at which CEH-18 is expressed, late in embryogenesis. Therefore, the embryonic lethality is most likely caused by disruption of ceh-18 function in the parent, as CEH-18 is not expressed early in embryogenesis and the lethality is not zygotically rescued. Furthermore, ceh-18 mutant embryos often have an abnormal spherical shape that is indicative of a very early defect in embryogenesis. Interestingly, symmetrical embryos are observed in the Drosophila mutants gurken, torso-like, and torso that disrupt signaling between follicle cells and the oocyte (Sprenger et al. 1989; Stevens et al. 1990; Neuman-Silberberg and Schüpbach 1993; Savant-Bhonsale and Montell 1993). It is possible that like the follicle cells in the Drosophila mutants, ceh-18 mutant sheath cells are defective in the production of a signal that normally induces oocyte asymmetry.

Our analysis indicates that ceh-18 also plays a role in directing gonad migration and is expressed by the dtc. Laser ablation experiments have demonstrated that the dtc leads gonad migration (Kimble and White 1981). Other homeo proteins have been implicated in the control of cell migration by acting in migrating cells (Salser and Kenyon 1992; Niehrs et al. 1993). ceh-18 might regulate expression of a guidance receptor in the dtc for migration into the mid-body region or production of extracellular guidance cues from the epidermis.

An important attribute of ceh-18 mutations is that they are incompletely penetrant. Because our strongest allele, ceh-18(mg57), is a good candidate for a null mutation (see Results), we suggest that incomplete penetrance is more likely to result from other genes with partially redundant activities.

We have isolated two classes of non-null ceh-18 alleles. Two alleles, $m g 58$ and $m g 62$, have significant in vivo activity despite lacking a POUhd. Likewise, $m g 61$ also retains partial in vivo function despite lacking a POUsp. In vitro binding studies have shown that both the POUsp and the POUhd make DNA contacts and are both required for high-affinity DNA binding (Sturm and Herr 1988; Ingraham et al. 1990; Kristie and Sharp 1990; Verrijzer et al. 1990a,b, 1992). Isolated POUhds and POUsps have been demonstrated to mediate low-affinity DNA binding in vitro (Sturm and Herr 1988; Ingraham et al. 1990; Kristie and Sharp 1990; Verrijzer et al. 1990b, 1992). This low-affinity in vitro DNA binding may not be sufficient to explain the partial in vivo function of mutants that lack the POUsp or the POUhd. Therefore, interactions with other proteins, possibly those postulated to have redundant activities (see above), may be important in vivo to stabilize DNA binding by these mutant $\mathrm{CEH}-18$ proteins and could contribute to the normal function of the wild-type protein. In addition, other regions of CEH-18, such as the amino-terminal acidic stretch, may also contribute to in vivo function.

Recently, the three-dimensional structure of the Oct-1
POU domain bound to DNA was determined by X-ray crystallography of the cocrystal (Klemm et al. 1994). These results show that both the POUsp and the POUhd constitute independent DNA-binding domains, both making major groove contacts on opposite faces of the DNA helix without interdomain protein-protein interactions. Thus, our genetic results are consistent with the $\mathrm{X}$-ray crystallographic results and show that each POU subdomain is able to function independently in the control of oocyte meiotic cell cycle arrest.

\section{Materials and methods}

Isolation of ceh-18

Standard molecular biological techniques were used. An amplified $\lambda \mathrm{gt} 10 \mathrm{cDNA}$ library from a mixed stage population of wildtype C. elegans (gift of S. Kim, Stanford University, CA) was screened with a mixture of two degenerate oligonucleotides POU-1 and POU-2, as described (Bürglin et al. 1989). Ten positive phage were obtained from $\sim 2 \times 10^{6}$ phage screened. A positive phage with the largest insert $(\phi 6)$ was sequenced completely on both strands using Sequenase v. 2.0 (U.S. Biochemical). The structure of the ceh-18 cDNA was verified further by directly sequencing DNA fragments PCR-amplified from oligo(dT)-primed first-strand cDNA. Genomic clones were isolated by screening cosmid genomic libraries using the $\$ 6 \mathrm{cDNA}$ as a probe. Two overlapping cosmids, C50A9 and LLC5, were isolated and positioned on the physical map by fingerprinting (Coulson et al. 1986). The positions of the intron/exon boundaries and the indicated intron sequences were determined by sequencing directly from cosmid DNA and DNA fragments amplified directly from genomic DNA. Intron sizes were determined exactly by sequencing or estimated by sizing restriction fragments amplified with flanking primers. The physical and genetic maps in the ceh-18 region were correlated as follows. The RFLPs mgP39 and mgP40 were detected by Southern hybridization of restriction enzyme digests (HindIII for $m g P 39$ and ClaI for $m g P 40$ ) of total genomic DNA from C. elegans var. Bristol and Bergerac, using the cosmids F14H9 and T14G12 as probes, respectively. Recombinants were isolated from the strain unc-78(e1217) lin-18(e620) lon-2(e678)/ + + + (Bergerac RW7000). Homozygous Non-Unc Lin Lon $|n=19|$ and Unc Non-Lin Non-Lon $(n=7)$ recombinants were analyzed by whole genomic Southern blots to give the genetic order unc-78 $(9 / 25)$ $m g P 40(4 / 25) m g P 39(12 / 25)$ lin-18. In adition, 6/6 Non-Unc Non-Lin Lon recombinants had the Bergerac pattern for both $m g P 39$ and $m g P 40$, whereas $4 / 4$ Unc Lin Non-Lon recombinants had the Bristol pattern for both $m g P 39$ and $m g P 40$.

\section{Isolation of Tcl insertions in ceh-18 and deletion derivatives}

Transposable elements were targeted using a PCR and sib-selection scheme (Ballinger and Benzer 1989, Kaiser and Goodwin 1990) as modified for C. elegans and its transposable elements (Rushforth et al. 1993; Zwaal et al. 1993). The positions of the Tc1 insertions were confirmed with multiple PCR reactions using flanking primers, followed by directly sequencing PCR products from both insertion junctions. Deletion derivatives resulting from imprecise excision of Tc1 from ceh-18(pk37::Tc1) were identified by PCR using cl8-39 (5' -CCCACACCAGTTTCCACAAATGGC-3') and c18-26 (5'-AGGCTAGAAAGTTCTACGGG-3') primers. Single worm PCR reactions were carried out as described (Williams et al. 1992). (Details of the PCR and sib-selection procedure can be obtained by anonymous ftp or 
gopher from weeds.mgh.harvard.edu.) The deletions were characterized by directly sequencing the PCR products shown in Figure 2. Upon isolation, the heterozygous deletion strains were outcrossed to wild type at least seven times, and the arms of the $\mathrm{X}$ chromosome were crossed off in genetic mapping experiments. ceh-18(mg57) was genetically mapped as follows. Unc Non-Lin Non-Lon recombinants and Non-Unc Lin Lon recombinants were selected from the strain + ceh-18(mg57) + + /unc-78(e1217) + lin-18(e620) lon-2(e678); the results were unc-78(e1217) 19/43 ceh-18(mg57) 24/43 lin-18(e620).

Preparation of $\alpha$-CEH-18Amg57 antibodies, Western blotting, immunofluorescence, and microscopy

Full-length CEH-18 was expressed in Escherichia coli starting with the first methionine in the cDNA. The cDNA sequence $\left(5^{\prime}\right.$-GCAAGAAATATG-3' $), 5^{\prime}$ to the ATG, was altered to $\left(5^{\prime}\right.$ GCATGCCATATG-3') using PCR. The entire restriction fragment subjected to PCR was sequenced to ensure that no errors were introduced by Taq polymerase. The resulting Ndel fragment was then cloned into pEt3a (Studier et al. 1990) to create pCEH-18T7. Antisera were produced by injecting gel-purified CEH-18 into two rabbits as described (Finney and Ruvkun 1990). Sera from both rabbits yielded identical results. Affinitypurified sera specific to the portion of CEH-18 deleted in ceh-

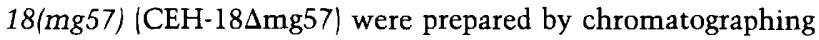

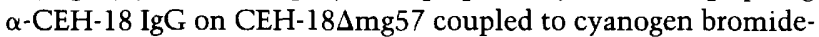
activated Sepharose 4B (Pharmacia). The plasmid (pCEH$18 \Delta \mathrm{mg} 57$ ) encoding a His-tagged derivative of CEH-18 corresponding to the portion of the protein deleted in ceh-18(mg57) was constructed as follows. The oligonucleotides cl8-45 (5'CGCGGATCCATCGAGGGTAGAGCAAATGGTCTGGGTGCTTCA-3') and c18-46 (5'-CGCGGATCCACTGTCATCATTGCTGGCTTG-3') were used in PCR reactions using pCEH$18 \mathrm{~T} 7$ as template. The resulting product was digested with BamHI and cloned into pQE-8 (Qiagen) cut with BamHI.

For Western blotting, protein extracts were prepared from newly hatched L1 stage animals by boiling for $30 \mathrm{~min}$ in $50 \mathrm{~mm}$ Tris-Cl $(\mathrm{pH} 6.8), 4 \%$ SDS, and $\beta$-mercaptoethanol. L1 stage animals were used because CEH-18 appears to be most stable at this stage. Similar Western blot results were obtained with other stages. The protein was transferred to nitrocellulose and analyzed with $\alpha$-CEH-18Dmg57 antibodies (1:5000) using the ECL detection system (Amersham Inc.) CEH-18 migrates slightly slower than the predicted molecular mass of $65 \mathrm{kD}$; however, as CEH-18 from $C$. elegans extracts comigrates with both in vitro-translated CEH-18 and CEH-18 expressed in E. coli (data not shown), this anomaly is likely to be an intrinsic property of the protein and not caused by post-translational modifications.

Immunostaining of fixed preparations was carried out using affinity-purifed antisera as described previously (Finney and Ruvkun 1990) and visualized using a Zeiss microscope equipped for fluorescence microscopy.

Embryos were mounted (Sulston et al. 1983) for microscopy and visualized using differential interference contrast microscopy. mAb NE2/1B4-14 was a gift of J. Rothman (University of Wisconsin, Madison).

\section{RT-PCR analysis of ceh-18(mg61)}

RNA was prepared from N2 and ceh-18(mg61), and first-strand cDNA was prepared using an oligo(dT) primer and SuperScript RNase $\mathrm{H}^{-}$Reverse Transcriptase (GIBCO-BRL). Nested PCR was conducted using SL1 and c18-26 primers in the first PCR reaction and c18-11 (5'-AGTCCATCTTTGTCGGGAGCCAGC-3') and c18-40 (5'-CCGAGAAATCAAACGTGCGAAT-
CAG-3') in the second PCR. The cDNA from ceh-18(mg61) was a mixture of two products: $70 \%$ was spliced at all introns except the intron 5 donor; $30 \%$ was spliced at the intron 5 donor to the novel acceptor $5^{\prime}$-TTACAT-3' formed by the deletion junction indicated in Figure 1. The spliced and unspliced PCR products were separated on a $4 \%$ nondenaturing polyacrylamide gel and sequenced directly.

\section{Acknowledgments}

We thank Jim McCarter, Ross Francis, and Tim Schedl for communicating their unpublished results, discussing the ceh-18 mutant phenotype, suggesting that we analyze the gonad sheath cells, and providing photographs for Figure 5, A and B. We thank Roger Brent, Sho Gottlieb, Liz Ryder, Terry Orr-Weaver, Tim Schedl, and the members of the Ruvkun, Kaplan, and Brent laboratories for critical reading of the manuscript and helpful discussions. Three anonymous referees provided a thorough critique that was helpful in revising the manuscript. We thank Thomas Bürglin for scintillating discussions of homeo boxes. We also thank Wendy Katz and Paul Sternberg for sharing strains and mapping information and Joel Rothman for $\mathrm{mAB}$ NE2/1B4-14. D.G. was supported by a National Institutes of Health postdoctoral fellowship. Y.K. was supported by a grantin-aid for creative basic research (Human Genome Program) from Ministry of Education, Science, and Culture, Japan. G.R. was supported in part by an American Cancer Society Faculty research award. This work was also supported by grants from Hoechst, A.G., and from the Human Frontiers Science Program.

The publication costs of this article were defrayed in part by payment of page charges. This article must therefore be hereby marked "advertisement" in accordance with 18 USC section 1734 solely to indicate this fact.

\section{References}

Andersen, B., M.D. Schonemann, S.E. Flynn, R.V. Pearse II, H. Singh, and M.G. Rosenfeld. 1993. Skn-1a and Skn-1i: Two functionally distinct Oct-2-related factors expressed in epidermis. Science 260: 78-82.

Austin, J. and J. Kimble. 1987. glp-1 is required in the germ line for regulation of the decision between mitosis and meiosis in C. elegans. Cell 51: 589-599.

Axton, J.M., F.L. Shamanski, L.M. Young, D.S. Henderson, J.B. Boyd, and T.L. Orr-Weaver. 1994. The inhibitor of DNA replication encoded by the Drosophila gene plutonium is a small, ankyrin repeat protein. EMBO J. 13: 462-470.

Ballinger, D.G. and S. Benzer. 1989. Targeted gene mutations in Drosophila. Proc. Natl. Acad. Sci. 86: 9402-9406.

Beanan, M.J. and S. Strome. 1992. Characterization of a germline proliferation mutation in $C$. elegans. Development 116: 755-766.

Bodner, M., J.-L. Castrillo, L.E. Theill, T. Deerinck, M. Ellisman, and M. Karin. 1988. The pituitary-specific transcription factor GHF-1 is a homeobox-containing protein. Cell 50: $267-275$.

Bürglin, T.R., M. Finney, A. Coulson, and G. Ruvkun. 1989. Caenorhabditis elegans has scores of homeobox-containing genes. Nature 341: 239-243.

Clerc, R.G., L.M. Corcoran, J.H. LeBowitz, D. Baltimore, and P.A. Sharp. 1988. The B-cell-specific Oct- 2 protein contains POU box-and homeo box-type domains. Genes \& Dev. 2: 1570-1581.

Coulson, A., J. Sulston, S. Brenner, and J. Karn. 1986. Towards a physical map of the genome of the nematode Caenorhabdi- 
tis elegans. Proc. Natl. Acad. Sci. 83: 7821-7825.

Finney, M. and G. Ruvkun. 1990. The unc-86 product couples cell lineage and cell identity in C. elegans. Cell 63: 895-905.

Finney, M., G. Ruvkun, and H.R. Horvitz. 1988. The C. elegans cell lineage and differentiation gene unc-86 encodes a protein with a homeodomain and extended similarity to transcription factors. Cell 55: 757-769.

Freeman, M. and D.M. Glover. 1987. The gnu mutation of Drosophila causes inappropriate DNA synthesis in unfertilized and fertilized eggs. Genes \& Dev. 1: 924-930.

Hartwell, L.H. 1991. Twenty-five years of cell cycle genetics. Genetics 129: 975-980.

Hirsh, D., D. Oppenheim, and M. Klass. 1976. Development of the reproductive system of Caenorhabditis elegans. Dev. Biol. 49: 200-219.

Hodgkin, J. 1983. Male phenotypes and mating efficiency in Caenorhabditis elegans. Genetics 103: 43-64.

Ingraham, H.A., R. Chen, H.J. Mangalam, H.P. Elsholtz, S.E. Flynn, C.R. Lin, D.M. Simmons, L. Swanson, and M.G. Rosenfeld. 1988. A tissue-specific transcription factor containing a homeodomain specifies pituitary phenotype. Cell 55: 519-529.

Ingraham, H.A., S.E. Flynn, J.W. Voss, V.R. Albert, M.S. Kapiloff, L. Wilson, and M.G. Rosenfeld. 1990. The POU-specific domain of Pit-1 is essential for sequence-specific, high affinity DNA binding and DNA-dependent Pit-1-Pit-1 interactions. Cell 61: 1021-1033.

Kaiser, K. and S.F. Goodwin. 1990. "Site-selected" transposon mutagenesis in Drosophila. Proc. Natl. Acad. Sci. 87: 16861690.

Kiff, J., D.G. Moerman, L.A. Schriefer, and R.H. Waterston. 1988. Transposon-induced deletions in unc-22 of C. elegans associated with almost normal gene activity. Nature 331: 631-633.

Kimble, J. and D. Hirsh. 1979. The postembryonic cell lineages of the hermaphrodite and male gonads of Caenorhabditis elegans. Dev. Biol. 70: 396-417.

Kimble, J. and J.G. White. 1981. On the control of germ cell development in Caenorhabditis elegans. Dev. Biol. 81: 208219.

Kimble, J., L. Edgar, and D. Hirsh. 1984. Specification of male development in Caenorhabditis elegans: The fem genes. Dev. Biol. 105: 234-239.

Kingsley, D.M. 1994. The TGF- $\beta$ superfamily: New members, new receptors, and new genetic tests of function in different organisms. Genes \& Dev. 8: 133-146.

Klemm, J.D., M.A. Rould, R. Aurora, W. Herr, and C.O. Pabo. 1994. Crystal structure of the Oct-1 POU domain bound to an octamer site: DNA recognition with tethered DNA-binding modules. Cell 77: 21-32.

Ko, H., P. Fast, W. McBride, and L.M. Staudt. 1988. A human protein specific for the immunoglobulin octamer DNA motif contains a functional homeobox domain. Cell 55: 135144.

Kristie, T.M. and P.A. Sharp. 1990. Interactions of the Oct-1 POU subdomains with specific DNA sequences and with the HSV $\alpha$-trans-activator protein. Genes \& Dev. 4: 23832396.

Masui, Y. and H.J. Clarke. 1979. Oocyte maturation. Int. Rev. Cytol. 57: 185-282.

Monuki, E.S., R. Kuhn, G. Weinmaster, B.D. Trapp, and G. Lemke. 1990. Expression and activity of the POU transcription factor SCIP. Science 249: 1300-1303.

Müller, M., S. Ruppert, W. Schaffner, and P. Matthias. 1988. A cloned octamer transcription factor stimulates transcription from lymphoid-specific promoters in non-B cells. Nature
336: 544-551.

Muslin, A.J., A.M. MacNicol, and L.T. Williams. 1993a. Raf-1 protein kinase is important for progesterone-induced Xenopus oocyte maturation and acts downstream of mos. Mol. Cell. Biol. 13: 4197-4202.

Muslin, A.J., A. Klippel, and L.T. Williams. 1993b. Phosphatidylinositol 3-kinase activity is important for progesteroneinduced Xenopus oocyte maturation. Mol. Cell. Biol. 13: 6661-6666.

Nebreda, A.R. and T. Hunt. 1993. The c-mos proto-oncogene protein kinase turns on and maintains the activity of MAP kinase, but not MPF, in cell-free extracts of Xenopus oocytes and eggs. EMBO I. 5: 1979-1986.

Nelson, G.A., K.K. Lew, and S. Ward. 1978. Intersex, a temperature-sensitive mutant of the nematode Caenorhabditis elegans. Dev. Biol. 66: 386-409.

Neuman-Silberberg, F.S. and T. Schüpbach. 1993. The Drosophila dorsoventral patterning gene gurken produces a dorsally localized RNA and encodes a TGF $\alpha$-like protein. Cell 75: 165-174.

Niehrs, C., C. Keller, K.W.Y. Cho, and E.M. De Robertis. 1993. The homeobox gene goosecoid controls cell migration in Xenopus embryos. Cell 72: 491-503.

Okamoto, K., H. Okawawa, A. Okuda, M. Sakai, M. Muramatsu, and H. Hamada. 1990. A novel octamer transcription factor is differentially expressed in mouse embryonic cells. Cell 60: 461-472.

Rosenfeld, M.G. 1991. POU-domain transcription factors: pouer-ful developmental regulators. Genes \& Dev. 5: 897-907.

Rosner, M.H., M.A. Vigano, K. Ozato, P.M. Timmons, F. Poirier, P.W.J. Rigby, and L.M. Staudt. 1990. A POU-domain transcription factor in early stem cells and germ cells of the mammalian embryo. Nature 345: 686-691.

Rushforth, A.M., B. Saari, and P. Anderson. 1993. Site-selected insertion of the transposon Tc1 into a Caenorhabditis elegans myosin light chain gene. Mol. Cell. Biol. 13: 902-910.

Ruvkun, G. and M. Finney. 1991. Regulation of transcription and cell identity by POU domain proteins. Cell 64: 475-478.

Sagata, N., M. Oskarsson, T. Copeland, J. Brumbaugh, and G.F. Vande Woude. 1988. Function of the c-mos proto-oncogene product in meiotic maturation in Xenopus oocytes. Nature 335: 519-525

Sagata, N., I. Daar, M. Oskarsson, S.D. Showalter, and G.F. Vande Woude. 1989. The product of the mos proto-oncogene as a candidate "initiator" for oocyte maturation. Science 245: 643-646.

Salser, S. and C. Kenyon. 1992. Activation of a C. elegans antennapedia homologue in migrating cells controls their direction of migration. Nature 355: 255-258.

Savant-Bhonsale, S. and D.J. Montell. 1993. torso-like enodes the localized determinant of Drosophila terminal pattern formation. Genes \& Dev. 7: 2548-2555.

Scheidereit, C., J.A. Cromlish, T. Gerster, K. Kawakami, C. Balmaceda, R.A. Currie, and R.G. Roeder. 1988. A human lymphoid-specific transcription factor that activates immunoglobulin genes is a homeobox protein. Nature 336: 552-557.

Scholer, H.R., S. Ruppert, R. Balling, N. Suzuki, K. Chowdhury, and P. Gruss. 1990. New type of POU domain in germ linespecific protein Oct-4. Nature 344: 435-439.

Shemanski, F.L. and T.L. Orr-Weaver. 1991. The Drosophila plutonium and pan gu genes regulate entry into $S$ phase at fertilization. Cell 66: 1289-1300.

Smith, L.D. 1989. The induction of oocyte maturation: Transmembrane signaling events and regulation of the cell cycle. Development 107: 685-699.

Sprenger, F., L.M. Stevens, and C. Nüsslein-Volhard. 1989. The 
Greenstein et al.

Drosophila gene torso encodes a putative receptor tyrosine kinase. Nature 338: 478-483.

Stevens, L., H.G. Frohnhofer, M. Klingler, and C. Nüsslein-Volhard. 1990. Localized requirement for torso-like expression in follicle cells for development of terminal anlagen of the Drosophila embryo. Nature 346: 660-663.

Studier, F.W., A.H. Rosenberg, J.J. Dunn, and J.W. Dubendorf. 1990. Use of T7 RNA polymerase to direct the expression of cloned genes. Methods Enzymol. 185: 60-89.

Sturm, R.A. and W. Herr. 1988. The POU-domain is a bipartite DNA-binding structure. Nature 336: 601-604.

Sturm, R.A., G. Das, and W. Herr. 1988. The ubiquitous octamer-binding protein Oct-1 contains a POU domain with a homeo box subdomain. Genes \& Dev. 2: 1582-1599.

Sulston, J., Z. Du, and K. Thomas. 1992. The C. elegans genome sequencing project: A beginning. Nature 356: 37-41.

Sulston, J.E., E. Schierenberg, J.G. White, and J.N. Thomson. 1983. The embryonic cell lineage of the nematode Caenorhabditis elegans. Dev. Biol. 100: 64-119.

Verrijzer, C.P., A.J. Kal, and P.C. van der Vliet. 1990a. The DNA binding domain (POU domain) of transcription factor oct-1 suffices for stimulation of DNA replication. EMBO I. 9: 1883-1888.

. 1990b. The oct-1 homeo domain contacts only part of the octamer sequence and full oct-1 DNA-binding requires the POU-specific domain. Genes \& Dev. 4: 1964-1974.

Verrijzer, C.P., M.J. Alkema, W.W. van Weperen, H.C. Van Leeuwen, M.J.J. Strating, and P.C. van der Vliet. 1992. The DNA binding specificity of the bipartite POU domain and its subdomains. EMBO I. 11: 4993-5003.

Ward, S. and J.S. Carrel. 1979. Fertilization and sperm competition in the nematode Caenorhabditis elegans. Dev. Biol. 73: 304-321.

Williams, B.D., B. Schrank, C. Huynh, R. Shownkeen, and R.H. Waterston. 1992. A genetic mapping system in Caenorhabditis elegans based on polymorphic sequence-tagged sites. Genetics 131: 609-624.

Zwaal, R.R., A. Broeks, J. van Meurs, J.T.M. Groenen, and R.H.A. Plasterk. 1993. Target-selected gene inactivation in Caenorhabditis elegans by using a frozen transposon insertion mutant bank. Proc. Natl. Acad. Sci. 90: 7431-7435. 


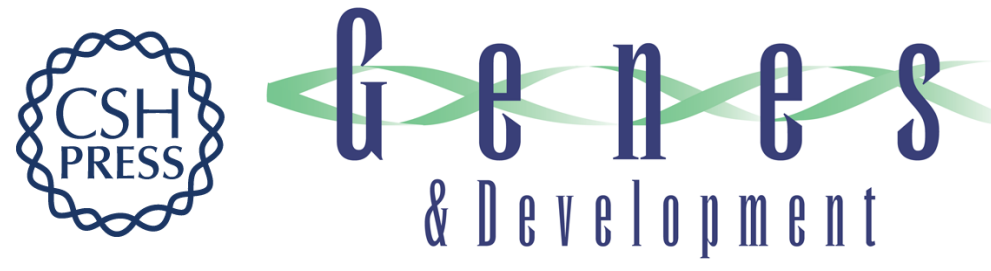

\section{Targeted mutations in the Caenorhabditis elegans POU homeo box gene ceh-18 cause defects in oocyte cell cycle arrest, gonad migration, and epidermal differentiation.}

D Greenstein, S Hird, R H Plasterk, et al.

Genes Dev. 1994, 8:

Access the most recent version at doi:10.1101/gad.8.16.1935

References This article cites 61 articles, 23 of which can be accessed free at:

http://genesdev.cshlp.org/content/8/16/1935.full.html\#ref-list-1

License

Email Alerting

Service

Receive free email alerts when new articles cite this article - sign up in the box at the top right corner of the article or click here.

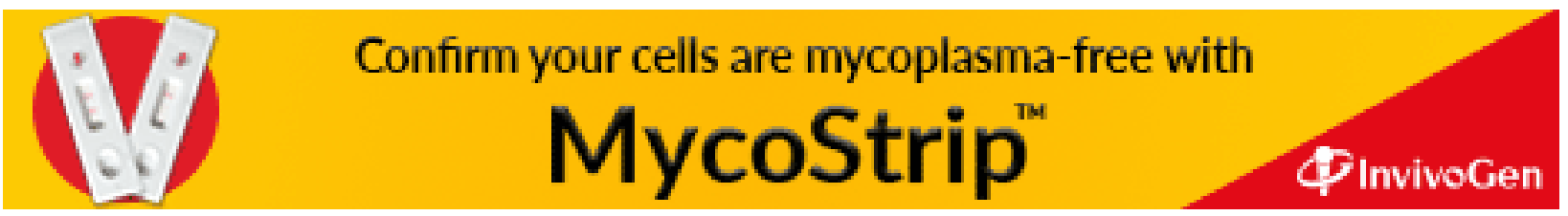

